\title{
A Quorum Sensing Regulated Small Volatile Molecule Reduces Acute Virulence and Promotes Chronic Infection Phenotypes
}

\author{
Meenu Kesarwani ${ }^{1,2 \times a}$, Ronen Hazan ${ }^{1,2}$, Jianxin $\mathrm{He}^{1,2}$, YokAi Que ${ }^{1,2}$, Yiorgos Apidianakis ${ }^{1,2}$, Biliana \\ Lesic $^{1,2 a b}$, Gaoping Xiao ${ }^{1,2}$, Valérie Dekimpe ${ }^{3}$, Sylvain Milot ${ }^{3}$, Eric Deziel ${ }^{3}$, François Lépine ${ }^{3}$, Laurence G. \\ Rahme $^{1,2 *}$
}

1 Department of Surgery, Harvard Medical School and Massachusetts General Hospital, Boston, Massachusetts, United States of America, 2 Shriners Burns Institute and Massachusetts General Hospital, Boston, Massachusetts, United States of America, 3 INRS-Institut Armand-Frappier, Laval, Québec, Canada

\begin{abstract}
A significant number of environmental microorganisms can cause serious, even fatal, acute and chronic infections in humans. The severity and outcome of each type of infection depends on the expression of specific bacterial phenotypes controlled by complex regulatory networks that sense and respond to the host environment. Although bacterial signals that contribute to a successful acute infection have been identified in a number of pathogens, the signals that mediate the onset and establishment of chronic infections have yet to be discovered. We identified a volatile, low molecular weight molecule, 2 -amino acetophenone (2-AA), produced by the opportunistic human pathogen Pseudomonas aeruginosa that reduces bacterial virulence in vivo in flies and in an acute mouse infection model. 2-AA modulates the activity of the virulence regulator MvfR (multiple virulence factor regulator) via a negative feedback loop and it promotes the emergence of $P$. aeruginosa phenotypes that likely promote chronic lung infections, including accumulation of las $R$ mutants, long-term survival at stationary phase, and persistence in a Drosophila infection model. We report for the first time the existence of a quorum sensing (QS) regulated volatile molecule that induces bistability phenotype by stochastically silencing acute virulence functions in $P$. aeruginosa. We propose that 2-AA mediates changes in a subpopulation of cells that facilitate the exploitation of dynamic host environments and promote gene expression changes that favor chronic infections.
\end{abstract}

Citation: Kesarwani M, Hazan R, He J, Que Y, Apidianakis Y, et al. (2011) A Quorum Sensing Regulated Small Volatile Molecule Reduces Acute Virulence and Promotes Chronic Infection Phenotypes. PLoS Pathog 7(8): e1002192. doi:10.1371/journal.ppat.1002192

Editor: Jenifer Coburn, Medical College of Wisconsin, United States of America

Received March 4, 2011; Accepted June 26, 2011; Published August 4, 2011

Copyright: (c) 2011 Kesarwani et al. This is an open-access article distributed under the terms of the Creative Commons Attribution License, which permits unrestricted use, distribution, and reproduction in any medium, provided the original author and source are credited.

Funding: This work was supported by a National Institute of Health grant (Al063433), a Shriners research grant (\#8770), and a Cystic Fibrosis Foundation grant (\#05GO) to LGR. RH was supported by a Shriners Hospitals Research Fellowship (\#8494). YAQ was supported by a Swiss National Science Foundation / Swiss Medical Association grant (\#PASMP3-123226) and a grant from the SICPA Foundation. The funders had no role in study design, data collection and analysis, decision to publish, or preparation of the manuscript.

Competing Interests: The authors have declared that no competing interests exist.

*E-mail: rahme@molbio.mgh.harvard.edu

wa Current address: Cincinnati Children's Hospital and Medical Center, Cincinnati, Ohio, United States of America

ab Current address: Danone Research, RD128, Palaiseau, France

\section{Introduction}

Bacteria excrete small molecules that act as specific chemical signals to positively regulate specialized processes [1], including the production of virulence factors important for pathogenic infection, host colonization, and interspecies microbial interactions [2]. Using interconnected multi-layered regulatory networks, such as quorum sensing (QS) networks, bacteria sense and respond to external and internal bacterial cell signals as well as environmental cues, thereby adapting to exploit target hosts. Adaptation and coordination of gene expression is particularly important for pathogenic microorganisms that need to colonize changing host environments since their ability to sense and respond to host environmental cues is crucial for their survival.

Pseudomonas aeruginosa is an opportunistic human pathogen that causes chronic and acute infections, and is a major agent of morbidity and mortality in cystic fibrosis (CF) patients. Establishment of chronic $P$. aeruginosa respiratory or wound infections requires a complex adaptive process that mediates essential physiological changes allowing bacterial cells to survive and persist in a dynamic host environment. Although insights into chronic infection pathways have been reported [3-7], the specific bacterial signals that may promote the transition and/or adaptation of known pathogens from an acute to a chronic infection remain unknown.

Many $P$. aeruginosa virulence factors associated with acute infections are controlled by QS [8]. This pathogen has an extensively studied complex QS-communication network that facilitates cross-talk between organisms and impacts many $P$. aeruginosa group-related behaviors including virulence [8]. There are at least three known QS systems in P. aeruginosa: two are dependent on the acyl-homoserine-lactone (AHL) QS transcription factors LasR and RhlR [9], and a third is dependent on the 4-hydroxy-2alkylquinolines (HAQs) LysR-type transcription factor MvfR (multiple virulence factor regulator) [10]. MvfR is critical for $P$. aeruginosa acute infection through its control of genes involved in the production of secreted virulence factors and in iron assimilation 


\section{Author Summary}

$P$. aeruginosa causes acute as well as chronic infections in humans. In this paper we report the identification of a $P$. aeruginosa small molecule, 2-AA, that modulates this pathogen's virulence to promote chronic infections. We show that the synthesis of 2-AA, responsible for the grapelike odor of $P$. aeruginosa cultures and of wound infections, is controlled by the multiple virulence factor regulator (MvfR) important for virulence in acute infections. 2-AA reduces the production of MvfR-regulated acute virulence factors, and attenuates acute virulence by negatively finetuning the MvfR regulon activity. Moreover, we show that 2-AA adapts $P$. aeruginosa for chronic infections by promoting mutations in a key acute virulence gene (lasR) and by prolonging bacterial survival. The findings presented here reveal the function of a new MvfR-regulated molecule, and highlight MvfR's importance as a highly promising target for the development of inhibitors that can simultaneously halt acute and chronic infections caused by $P$. aeruginosa, and possibly by other pathogenic bacteria. This study uncovers insights that paradigmatically pave the way for the search of 2-AA-like small volatile molecules that promote pathogen adaptation and establishment of chronic infections caused by foreboding human pathogens.

[10-13]. This regulator controls HAQ signaling and its own activity by positively regulating the expression of genes in the pqsABCDE [14] and phnAB [10] operons. These operons encode enzymes that catalyze the biosynthesis of at least 59 distinct low molecular weight compounds, most of which are structurally related to HAQs. While two of the most abundant HAQs, [4-hydroxy-2-heptylquinoline (HHQ) and 3,4-dihydroxy-2-heptylquinoline (Pseudomonas Quinolone Signal-PQS)] [14-16], function in vivo as ligands that bind and activate $\mathrm{MvfR}[14,17]$, the biological functions of other PqsABCD/PhnAB biosynthetic products remain elusive.

In this study, we show that one of these abundant MvfRregulated non-HAQ low molecular weight molecules, 2-aminoacetophenone (2-AA), that is used to diagnose $P$. aeruginosa infections in humans [18], reduces acute virulence by negatively fine-tuning the transcription and synthesis of the MvfR ligand HHQ and promotes changes that are critical for pathogen adaptation and important for chronic infection.

\section{Results/Discussion}

\section{2-AA Synthesis Is Controlled by MvfR but Is Not Required for the Activation of Its Regulon}

To determine the functions of the abundant MvfR-regulated small molecules, we first compared the liquid chromatography/ mass spectrometry (LC/MS) total ion chromatograms of culturefree supernatants from highly pathogenic wild-type $P$. aeruginosa (PA14) cells versus those of isogenic mvfR mutant cells. As shown in Figure 1A, the mofR versus PA14 supernatant lacked HHQ and PQS, as well as three other abundant low molecular weight compounds: the HAQ molecule 4-hydroxy-2 heptylquinoline $\mathcal{N}$ oxide (HQNO) [19], 2,4-dihydroxyquinoline (DHQ [20], and the non-HAQ molecule 2-AA. 2-AA is a relatively simple, non-HAQ volatile molecule responsible for the grape-like odor of $P$. aeruginosa cultures as well as burn wounds infected with $P$. aeruginosa $[18,21]$. Along with DHQ and HQNO, 2-AA is also produced and excreted by the HAQs-producing bacterium Burkholderia thailandensis [23] (Figure S1). Because HHQ and PQS both induce pqsABCDE expression [14], we investigated whether these three additional abundant molecules also induce expression of these genes. Maximum levels of 2-AA in the cell supernatant vary from micromolar to millimolar range depending on the growth medium used [18,22]. We used Luria-Bertani (LB) broth media in experiments examining the effects of exogenous 2-AA supplementation on pqs operon gene transcription. We chose to use LB broth because it supports lower levels of 2-AA production (37.5 $\mu \mathrm{M}=5 \mu \mathrm{g} / \mathrm{ml}$ Figure $1 \mathrm{~B})$ than other media [18]. Using a $p q s A$-green fluorescence protein (GFP)(ASV)-transcriptional reporter fusion in a $p q s A:: H$ double mutant background that does not produce any of these molecules (Figure S2), we exogenously added to LB media the above molecules. HQNO only modestly induced pqsABCDE expression, while DHQ and 2-AA did not induce pqsABCDE expression (Figure 1C). This finding indicates that unlike HHQ and PQS, 2-AA and DHQ molecules may have biological roles other than activating pqs operon transcription.

\section{2-AA Down-regulates the Expression of MvfR-regulated Loci}

The kinetics and dose-dependency effects of exogenously added 2-AA and DHQ on $p q s A$ regulation were examined in greater detail using WT cells carrying the $p q s A$-GFP(ASV) transcriptional reporter fusion. Figure 2A shows that 2-AA, but not DHQ(Figure $\mathrm{S} 3 \mathrm{~A})$, greatly reduced $p q s A$ expression, in a dose-dependent manner, with 2-AA achieving the strongest inhibition at $200 \mu \mathrm{g} /$ $\mathrm{ml}(1.5 \mathrm{mM})$. Bacterial growth was unaffected by either 2-AA or DHQ (Figure S3B and C). In light of these results, we focused our subsequent experimental efforts on 2-AA.

We visualized pqsA-GFP expression under a fluorescent microscope in the presence of a range of 2-AA concentrations. Surprisingly, but in accordance with the established dose-dependent effects of 2AA, only a subpopulation of the cells showed a shut-down of $p q s A$ GFP activity in the presence of $50 \mu \mathrm{g} / \mathrm{ml}(0.375 \mathrm{mM}) 2-\mathrm{AA}$ (Figure 2B and C); a statistically significant number of cells had turned off the pqsA expression though some still fluoresced strongly. No fluorescing cells were seen at $200 \mu \mathrm{g} / \mathrm{ml}$ 2-AA (Figure 2B and C). Thus 2-AA appears to promote phenotypic heterogeneity in a genetically "homogenous" population and silence pqs operon expression in a fraction of the cells, suggesting that MvfR active and inactive cells co-exist to achieve a bistable phenotype [24]. The size of the 2-AA responsive population increased with higher 2-AA concentrations. The need for higher concentrations of 2-AA to produce significant detectable transcriptional changes may be due to the compound affecting only a subpopulation of cells.

2-AA inhibition of MvfR is likely mediated via negative feedback regulation given that MvfR controls 2-AA synthesis (Figure 1A). To corroborate our pqsA expression data, we measured levels of HHQ in 2-AA treated cells and found that HHQ production was also inhibited by 2-AA in a dose-dependent manner (Figure 2D). Consistent with the view that 2-AA downregulates the MvfR regulon, we observed that 2-AA decreased production of pyocyanin (Figure 2E) and pyoverdine (Figure 2F), virulence factors whose synthesis depends on MvfR. A time course study of 2-AA production (Figure 1B) showed that 2-AA levels did not significantly decrease as occurs for the MvfR activators HHQ and PQS (Figure 1B), indicating that the production kinetics and stability of 2-AA are distinct from those of the MvfR activators. Together, this convergence of data strongly suggests that 2-AA has the novel biological activity of silencing the MvfR regulon.

\section{2-AA Down-regulates pqs $A B C D E$ Operon Expression via MvfR, and by Targeting HAQ Biosynthesis Enzymes}

To elucidate the mechanism by which 2-AA inhibits the MvfR regulon, we administered 2-AA together with HHQ to PAl4 
A
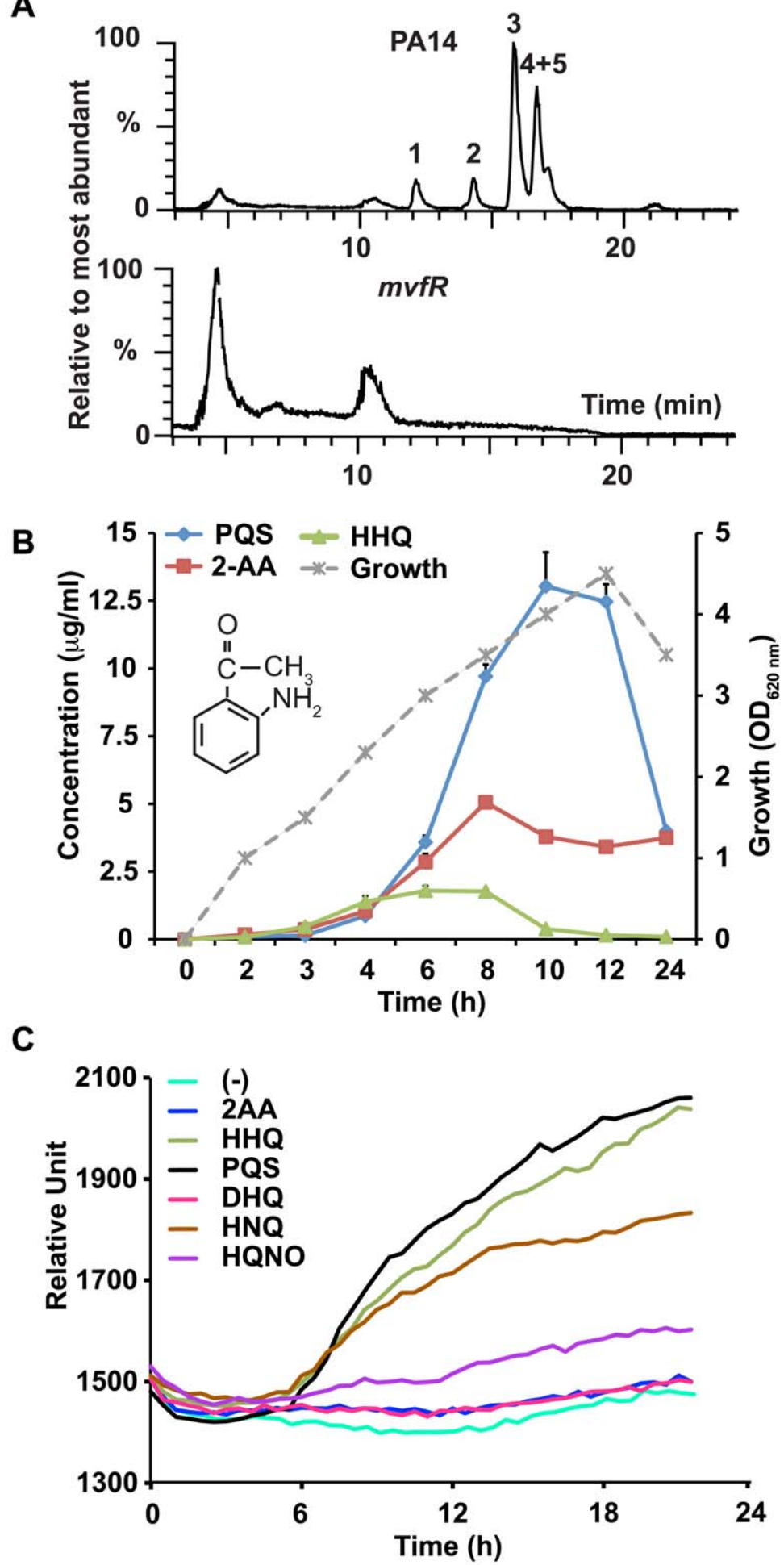

Figure 1. 2-AA synthesis is controlled by MvfR. (A) LC/MS total ion chromatograms show the relative percentage of the most abundant small molecules in P. aeruginosa (PA14) (upper panel) and isogenic mvfR mutant (lower panel) supernatants after $9 \mathrm{~h}$ of growth. The most abundant molecules in PA14 cultures that were absent in mvfR mutant cultures were: DHQ (1); 2-AA (2); HQNO (3); and HHQ+PQS (4+5). The abundant peaks shown in mvfR are negligible compared to the amount of HHQ or PQS produced by PA14 since the percentage value on the $\mathrm{Y}$ axis is drawn with respect to the most abundant molecule detected. (B) Production kinetics of 2-AA in PA14 supernatants in LB. PA14 growth is shown as OD $600 \mathrm{~nm}$ on the secondary $Y$ axis versus time. The chemical structure of 2-AA is shown in the inset. (C) 2-AA is not a MvfR co-inducer. MvfR-dependent pqsAGFP(ASV) expression in the pqsA::pqsH mutant with or without exogenous molecules $(10 \mu \mathrm{g} / \mathrm{ml})$, reported as relative fluorescence versus time, averaged for six replicates. doi:10.1371/journal.ppat.1002192.g001 
A

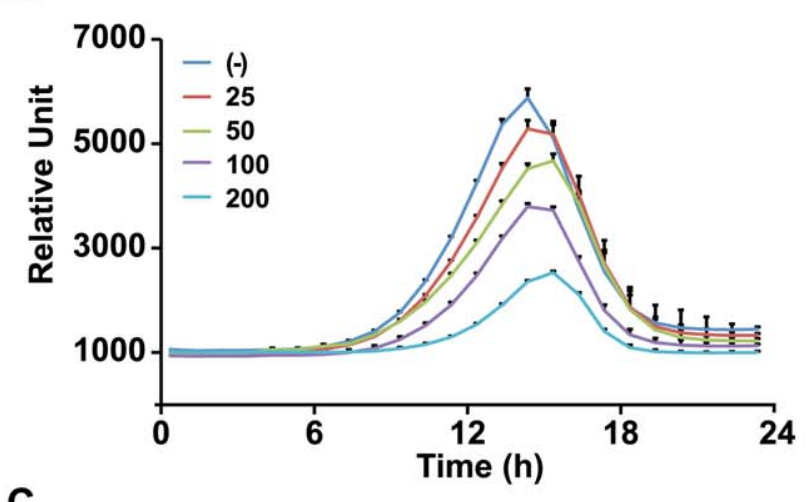

C

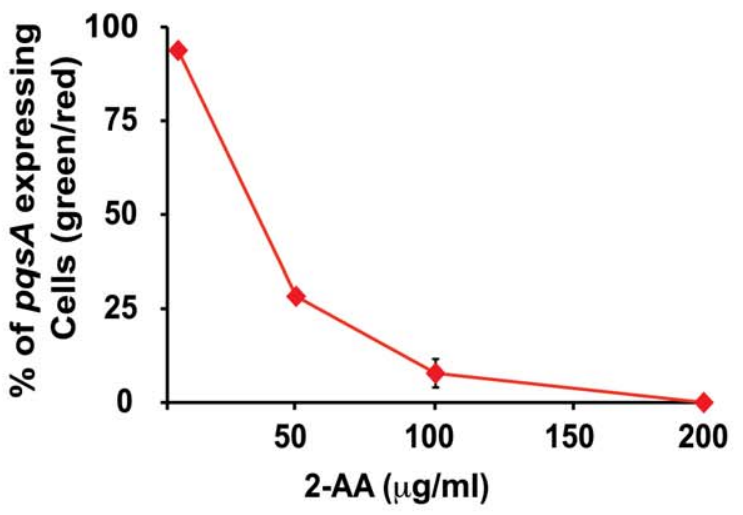

B

$(-)$
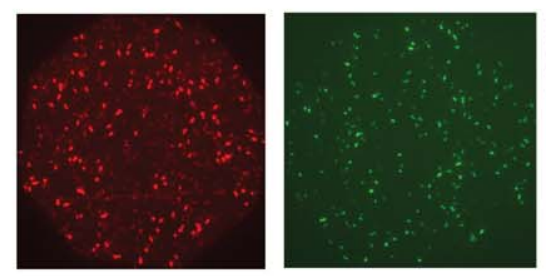

$\begin{array}{lll}\bar{\delta} & \overline{8} & \bar{\delta} \\ 0 & 0 & 0 \\ \dot{v} & \dot{0} & 0 \\ v & v & \mathrm{v}\end{array}$

50
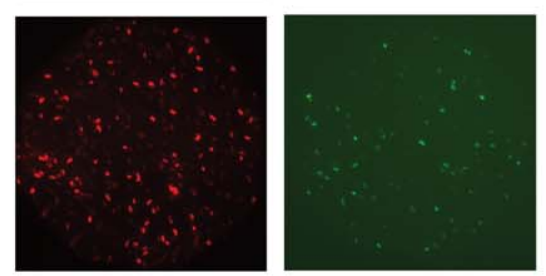

100
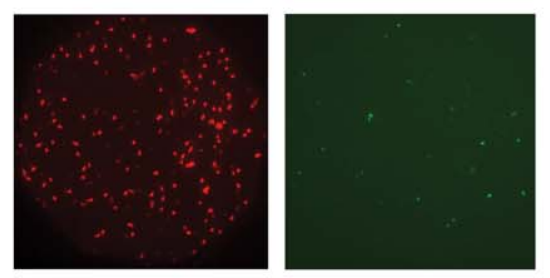

200
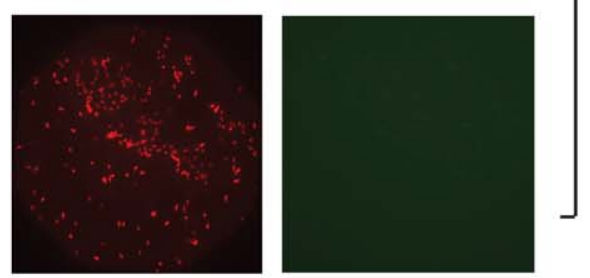

F

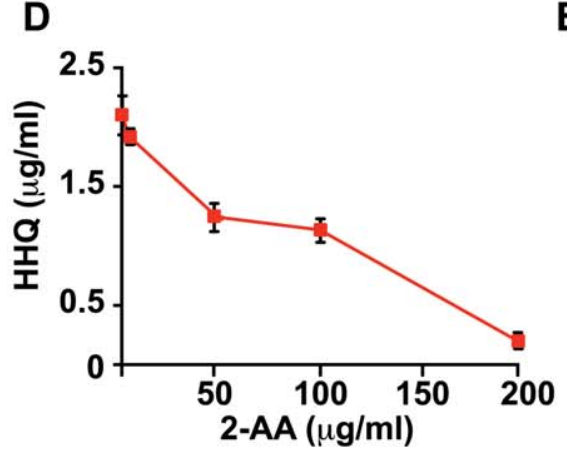

E
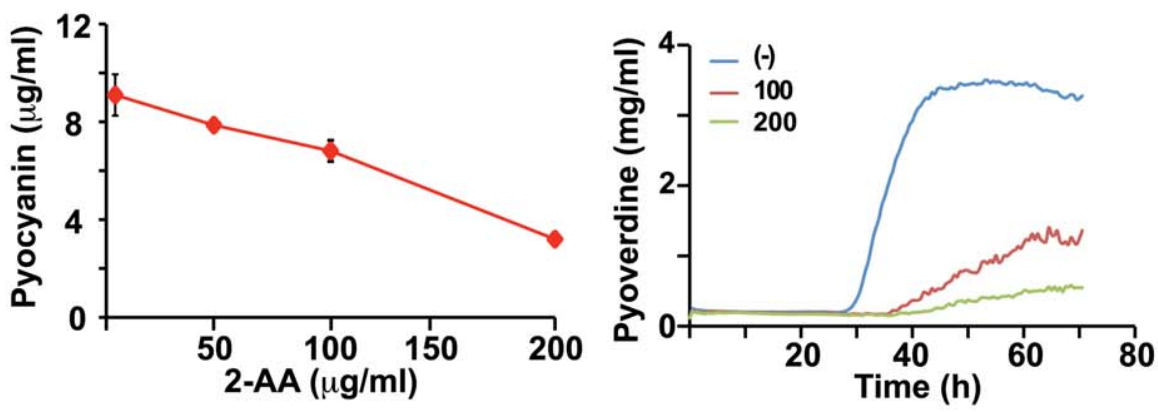

Figure 2. 2-AA silences MvfR regulon in a subpopulation of cells and restricts HAQ mediated QS signaling relevant in acute infection. (A) Quantification of pqsA-GFP(ASV) expression in PA14 cells in response to increasing 2-AA concentration ( $\mu \mathrm{g} / \mathrm{ml})$; the error bar represents the standard deviation of the 6 replicates. The difference in fluorescence intensity at the peak was statistically significant at all concentrations with $p$ values $<0.005$. (B) Expression of $p q s A-G F P(A S V)$ in response to 2-AA ( $\mu \mathrm{g} / \mathrm{ml})$. Images of total number of cells in the optical field as assessed by membrane staining (red) and bacterial cells expressing pqsA-GFP(ASV)(green). (C) Quantification of pqsA expressing cells (percentage of green/red) in response to each 2-AA concentration. (D) Production of HHQ in supernatants collected from PA14 cells (OD 2.0) with exogenously added 2-AA at $0-200 \mu \mathrm{g} / \mathrm{ml} \mathrm{HHQ}$ levels were quantified in triplicate by LC/MS. The error bars represent the standard deviation from triplicate samples. (E) Levels of pyocyanin in PA14 cultures grown (to OD 3.0) in LB and LB supplemented with varying (0-200 $\mu \mathrm{g} / \mathrm{ml}$ ) concentrations of 2-AA. Error bars represent standard deviation of the triplicate samples. These experiments were repeated at least three times with similar results. (F) Kinetics of pyoverdine production in the presence of 100 and $200 \mu \mathrm{g} / \mathrm{ml}$ of 2-AA. (-) indicates no exogenously added 2-AA.

doi:10.1371/journal.ppat.1002192.g002

isogenic pqsA::pqsH double mutant cells, which do not produce any HAQs [14] or 2-AA (Figure S2) but have functional MvfR. The expression of the $p q s A$ reporter in $p q s A:: p q s H$ cells requires activation of MvfR. While exogenous addition of HHQ to these cells induced $p q s A$ reporter expression via activation of MvfR, co-addition of 2$\mathrm{AA}$, at $100 \mu \mathrm{g} / \mathrm{ml}(0.75 \mathrm{mM})$ and above, attenuated this expression in a dose-dependent manner, suggesting that 2-AA may negatively impact the MvfR-regulated operon pqsABCDE at the transcriptional level (Figure 3A) via MvfR. Unlike other anthranilic acid analogs, which act on PqsA activity and inhibit the synthesis of MvfR ligands [25], the apparent 2-AA inhibition described here can be regarded as independent of PqsA since the pqsA::pqsH mutant was used in these experiments. Moreover, 2-AA did not perturb MvfR protein levels or MvfR ligand stability (data not shown).

To assess whether down-regulation of MvfR activity by 2-AA is due to reduced ligand levels, we engineered mvfR mutant cells to 
A

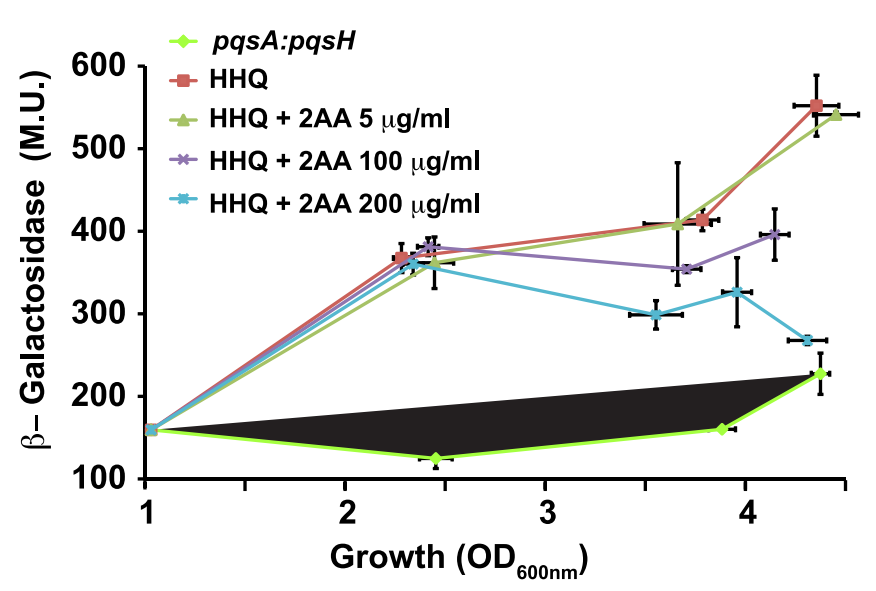

C

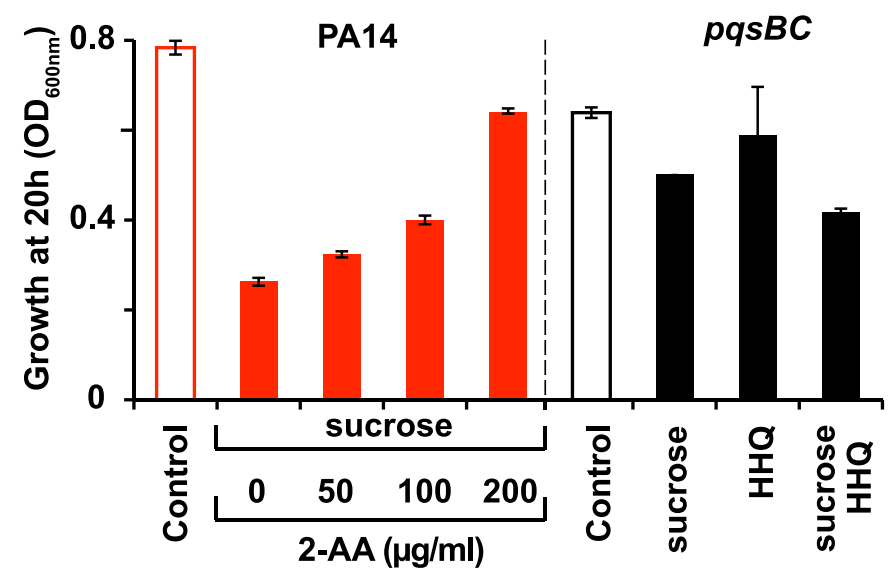

B

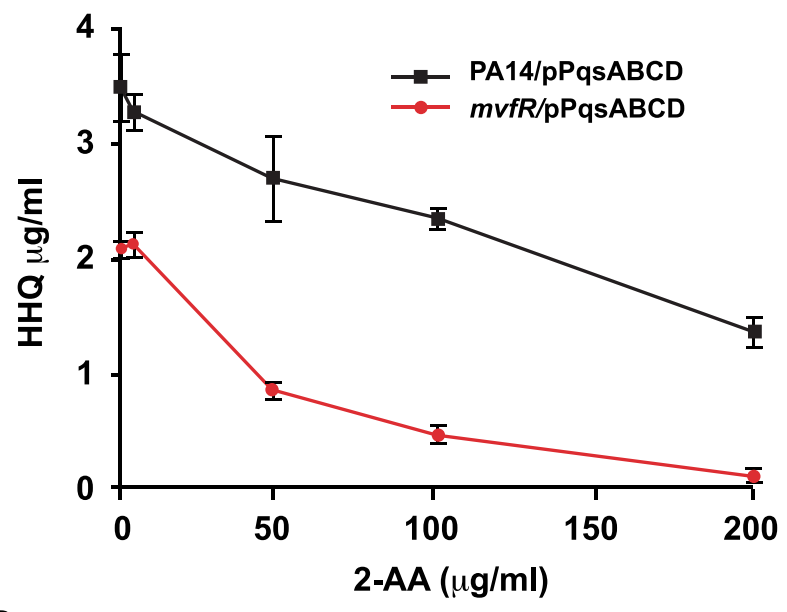

D

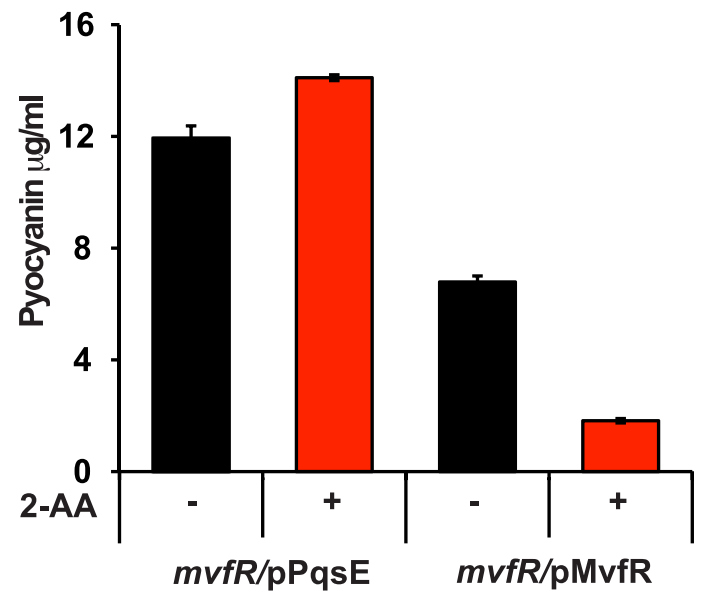

Figure 3. Negative regulation of the MvfR regulon by 2-AA is a result of down-regulation of pqsABCDE expression and interference with MvfR activity via inhibition of $\mathrm{HHQ}$ biosynthesis. (A) pqsA promoter response was assessed by measuring pqsA-LacZ expression in the PA14 isogenic pqsA::pqsH double mutant in the presence of HHQ $(10 \mu \mathrm{g} / \mathrm{ml})$ or HHQ together with $2-\mathrm{AA}$ at the indicated concentrations. $\beta$ galactosidase activity is given in Miller Units, and plotted against growth assessed at $\mathrm{OD}_{600 \mathrm{~nm}}$. The experiment was repeated three times with similar results. (B) Levels of HHQ in the supernatant (OD 2.0) of PA14 and mvfR mutant cells constitutively expressing pqsABCD on a plasmid. $\mathrm{HHQ}$ levels were quantified in triplicate by LC/MS. The error bars represent the standard deviation of triplicate samples. (C) Growth of PA14 and pqsB::C mutant cells carrying $p q s A-S a c B$ after $20 \mathrm{~h}$ of inoculation in the presence or absence of sucrose (10\%), and/or with exogenously added various concentrations of 2AA. The $p q s A$ promoter of $p q s A-S a c B$ in the $p q s B:: C$ mutant was induced by exogenous addition of $10 \mu \mathrm{g} / \mathrm{ml} \mathrm{HHQ}$ where indicated. (D) Concentration of pyocyanin in mvfR mutant cells (OD 3.0) over-expressing MvfR or PqsE under a constitutive promoter in the presence or absence of 2-AA (200 $\mu \mathrm{g} /$ $\mathrm{ml}$ ). Error bars represent standard deviations of triplicate samples. These experiments were repeated at least three times with similar results. doi:10.1371/journal.ppat.1002192.g003

synthesize HHQ independently of MvfR by constitutively expressing pqsABCD. These cells produced HHQ in the absence of 2-AA whereas HHQ production decreased in the presence of 2$\mathrm{AA}$ in a dose-dependent manner (Figure 3B), indicating that inhibition of the MvfR regulon can also occur independently of MvfR. This post-transcriptional inhibition could be mediated through interference with ligand biosynthesis.

The $p q s A B B C D E$ operon gene $p q s A$ is required for the synthesis of 2-AA and HHQ (Figure S2). In our effort to understand 2-AA biosynthesis, we created various mutants in the PQS operon. Surprisingly, the pqs $B:: C$ mutant produced 2-AA in the absence of HHQ (Figure S2), demonstrating that neither $p q s B$ and $p q s C$ is required for 2-AA synthesis. Addition of $\mathrm{PQS}$ to $p q s B:: C$ mutant cultures induced $p q s$ operon transcription, resulting in WT levels of 2-AA (Figure S2). However, as expected the addition of PQS did not result in production of HHQ (data not shown).
We used $p q s B:: C$ mutant cells with an additional, more sensitive reporter system to further assess the effects of endogenous 2-AA produced by the pqsB::C mutant on transcription of the mvfR regulon and its biological relevance in the absence of HHQ as well as to quantify 2-AA effects on the pqs operon. We fused the pqsA promoter to the Bacillus subtilis sacB gene that codes for the levansucrase product, which is toxic when cells are grown in the presence of sucrose. The $s a c B$ gene has previously been incorporated into allelic exchange vectors as a means of counterselection [23]. As shown in Figures 3C and S4, PA14 cells with the $p q s A-s a c B$ fusion gene incorporated stably into their chromosome did not grow in the presence of sucrose, while the corresponding isogenic pqs $B:: C$ mutant cells did grow significantly, corroborating the findings that 2-AA suppresses $p q s A$ promoter activation and indicating that this effect is stronger in the absence of HHQ. Bacterial cell proliferation occurred even following exogenous 
addition of $\mathrm{HHQ}$, which promotes further induction of the pqs operon (Figure 3C and S4). Importantly, the endogenous level of 2-AA in the $p q s B:: C$ mutant cells in presence of the inducer, had a suppression efficacy comparable to $100 \mu \mathrm{g} / \mathrm{ml}$ of exogenously added 2-AA Figure 3C. These results are physiologically important and consistent with the putative role of 2-AA in down-regulation of $\mathrm{MvfR}$ regulon. These results also suggest there may be limited uptake of exogenously added 2-AA thereby requiring addition of higher concentrations of 2-AA to generate a physiological response by exogenously added 2-AA.

The last gene in the pqs operon, pqsE, is essential for pyocyanin production [16,26-27], but dispensable for HAQ synthesis $[12,15]$. Importantly, 2-AA did not reduce pyocyanin in an mvfR mutant that constitutively expressed $p q s E$, even though it efficiently inhibited pyocyanin production when MvfR was constitutively expressed (Figure 3D). Hence we can deduce that 2-AA negative regulation of the $\mathrm{MvfR}$ regulon is a result of the down-regulation of pqsABCDE operon expression and interference with MvfR activity upstream of PqsE, via inhibition of HHQ biosynthesis.

\section{2-AA Treatment Reduces the Mortality of PA14-infected Flies and Mice}

We have shown previously that $P$. aeruginosa pathogenesis can be studied in Drosophila melanogaster [28-30]. Drosophila shares striking similarities with mammals in terms of its overall physiology and innate immunity signal transduction pathway components [28,31]. $P$. aeruginosa strain PAl4 is highly virulent in flies, causing high mortality; meanwhile, mvfR mutants exhibit reduced virulence, causing reduced mortality [30]. Therefore, since 2-AA negatively regulates $\mathrm{MvfR}$, we first tested whether it reduces $P$. aeruginosa virulence in Drosophila. As shown in the Figure 4A, flies co-injected with $P$. aeruginosa and 2-AA succumb to infection significantly later than flies injected with only $P$. aeruginosa.

To confirm the in vivo efficacy of 2-AA in attenuating the virulence of PA14 cells and validate the above findings in a mammalian model of infection, we used the well-studied acute mouse burn and infection model [32], in which we have shown previously that mofR mutant cells cause attenuated virulence $[10,25]$. Indeed, as shown in Figure 4B, 2-AA also attenuated the virulence of PA14 cells in mice. Mice inoculated with PA14 and injected once with 2-AA survived significantly longer than control mice inoculated with PA14 alone. Importantly, this effect could not have been due to reduced PA14 proliferation since 2-AA did not affect the bacterial colony forming units (CFUs) in the muscle tissue underlying the burn injury and infection site (Figure 4C). Importantly, 2-AA greatly hampered the systemic spread of bacteria in the blood of the infected mice (Figure 4D), which is a significant problem in humans with $P$. aeruginosa infections. Silencing of MvfR regulon activity, and thus of acute virulence factor gene expression, is likely responsible in large part for the reduced systemic dissemination of PA14 cells and attenuated PA14 virulence observed.

\section{2-AA Promotes the Emergence of $P$. aeruginosa Phenotypes that likely Promote Chronic Lung Infections}

One may wonder why a pathogen such as $P$. aeruginosa would produce a molecule that decreases its own virulence. However, given that successful adaptation of an organism depends on its ability to regulate gene expression in response to its changing environment and thereby maximize its long-term survival, the existence of such a mechanism should not be surprising. There is ongoing debate regarding the role of QS in chronic infection due to inactivation of LasR in P. aeruginosa isolates from CF sputum, while a lack of QS has been proposed to facilitate adaptation during a chronic infection [33]. Since 2-AA down-regulates the expression of QS-related acute virulence functions, we questioned if the same molecule could promote other functions that support adaptation during chronic infections. We therefore examined a variety of phenotypes associated with chronic infection by $P$. aeruginosa.

A significant fraction of $P$. aeruginosa cells isolated from chronically infected CF patients accumulate multiple mutations in genes affecting acute virulence functions, including mucA, the regulator of alginate production, the QS regulator LasR, type III secretion system, multidrug efflux pumps, genes involved in motility, and DNA repair genes such as mutS [2,34-38]. Mutations in the las $R$ gene are particularly notable, not only because they accumulate in bacteria colonizing the lungs of chronically infected $\mathrm{CF}$ patients, but also because they have been shown to promote long-term growth and survival of CF isolates in vitro [33]. Therefore, we first examined the frequency of occurrence of las $R$ mutations in populations of $P$. aeruginosa grown in the presence of increasing concentrations of 2-AA. We found that PA14 cells exposed to increasing 2-AA concentrations for $10 \mathrm{~d}$ accumulated significantly more las $R$ mutations than untreated cells (Figure 5A). Sequence analysis showed that these las $R$ mutant lines harbor simple deletions or single nucleotide non-synonymous mutations in the las $R$ gene that produce inactive LasR protein (Table 1). One of the las $R$ mutant lines also carried mutations in the intergenic region of the fle $Q$ flagellar gene regulator, which is important for motility, and five clones carried mutations in the intergenic region of mexT, a regulator of multidrug efflux. Mutations in these genes lead to loss of flagellar motility and antibiotic resistance, respectively [39-40]. However, no mutations in the DNA repair gene $m u t S$, in type III secretion system genes (exs $A, p s c Q$ and $p o p D)$, or in the virulence factor $v f R$ or $r p o \mathcal{N}$, which are also associated with chronic infections [2], were identified in any of the las $R$ mutant lines sequenced. Additionally, 2-AA does not appear to be mutagenic, as it did not stimulate mutagenesis in a standard Ames test (data not shown). We did not identify any mutation in las $R$ within a day of incubation when silencing of $m v f R$ was observed, suggesting that it's silencing is not due to the loss of las $R$. Nevertheless, the ability of 2 -AA to promote las $R$ mutations was particularly pronounced after $10 \mathrm{~d}$ of incubation in isogenic mut $S$ cells (Figure 5A), which are defective in DNA repair function. In contrast to the 2-AA dependent non-linear accumulation of las $R$ mutants observed in the WT background, a more linear accumulation of las $R$ mutants in the mut $S$ mutant background is observed (Figure 5A). These data suggest that once a DNA repair mechanism is compromised, as in mut $S$ mutants commonly found in $P$. aeruginosa cultures from CF sputum [37-38], 2-AA effect is more prominent.

Although the mechanisms and advantages of las $R$ mutations are not clearly understood, it has been proposed that las $R$ mutation may provide a growth advantage [33]. We further tested the effects of 2-AA on long-term survival of $P$. aeruginosa. When grown under the condition of limited iron and aeration, PA14 cells reach stationary phase within 10-12 $\mathrm{h}$ and undergo significant lysis after $40 \mathrm{~h}$ (Figure 5B). However, addition of 2-AA inhibited entry into the lytic phase and the treated cells remained in stationary phase, promoting bacterial cell long-term survival (Figure 5B). To investigate whether 2-AA can also promote long-term survival in vivo, we developed a non-vertebrate, whole animal persistence infection assay in Drosophila melanogaster. Using the fly- $P$. aeruginosa feeding assay [28], flies were fed for $2 \mathrm{~d}$ with $P$. aeruginosa WT (PA14), 2-AA non-producer PAl4 isogenic mutant strain pqsA, and the 2-AA producer strain $p q s B:: C$. Flies were then transferred onto 
A

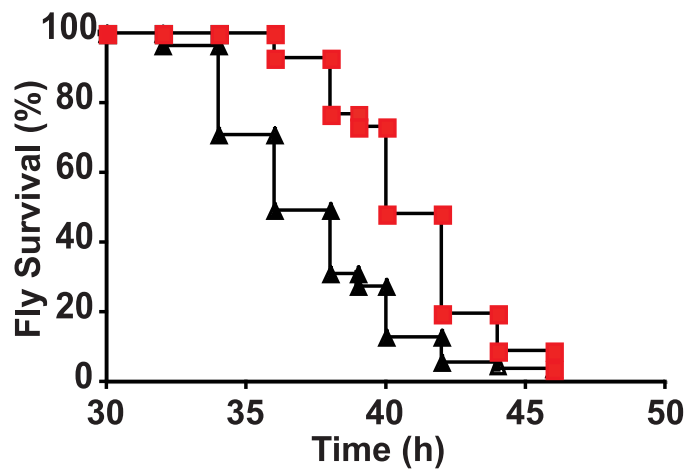

C

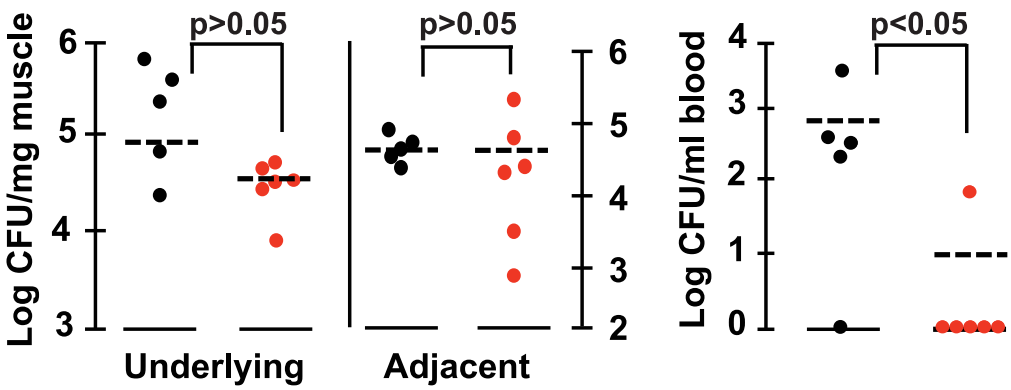

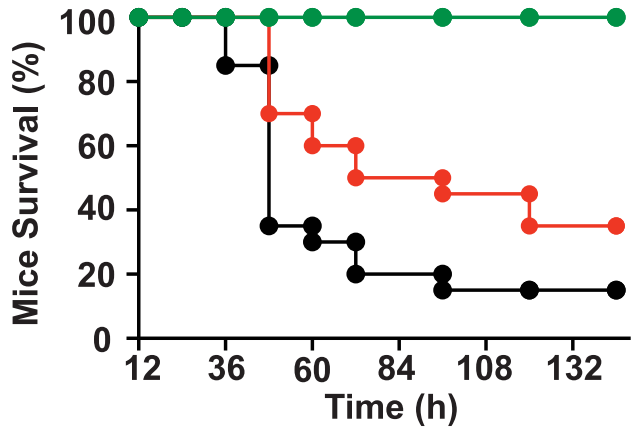

D Time (h)

Figure 4. 2-AA reduces $P$. aeruginosa virulence. (A) Survival kinetics of flies injected with a PA14 bacterial suspension with ( $\sim 1.6$ ng/fly) and without 2-AA. Data were averaged from two experiments with $n(P A 14)=55$ and $n(P A 14+2-A A)=56$. Significance of difference of survival rate was calculated using the log-rank test of the Kaplan Meier survival estimate $(p=0.0056)$. (B) Survival rates of mice infected with PA14 versus PA14 $+67 \mu g$ of $2-A A /$ mouse. The data correspond to the averages of two independent experiments, with $n(P A 14)=20$ and $n(P A 14+2-A A)=20$. Significance of difference of survival rates was calculated using the Kaplan-Meier method ( $p=0.03$ ), with a hazard ratio of $1.8932(95 \% \mathrm{Cl}, 1.0664$ to 6.0718$)$. (C and D) Bacterial loads in the local and adjacent muscle and in blood were determined for control and 2-AA treated mice, at $20 \mathrm{~h}$ post-burn and infection. The statistical significance of the CFU/mg muscle tissue differences between the control and experimental mice were determined using the MannWhitney test for independent samples, with $p=0.43$ for the difference in the underlying and adjacent muscle in response to 2 -AA, and $p=0.045$ for the difference in the blood in response to 2-AA. CFU data are presented as log 10. Black PA14, red PA14+2-AA, green 2-AA only. doi:10.1371/journal.ppat.1002192.g004

bacteria-free food, and the CFUs were quantified at $7 \mathrm{~d}$ postfeeding. Bacterial load decreased over time in the $p q s A$-infected flies, while flies infected with the 2-AA producing strains PA14 and pqs $B:: C$ sustained $\sim 3 \log$ greater CFUs (Figure $5 \mathrm{C}$ ), indicating that 2-AA helps bacteria to survive and persist, and thus promotes better fitness in a dynamic host environment. Due to the longer incubation duration, we cannot rule out the possibility that the persistence seen here may be due to las $R$ mutation induced by 2AA. Together with the above in vitro studies, these in vivo results corroborate the view that 2-AA plays a key role in switching cells to a phase that promotes concomitant adaptations that enable $P$. aeruginosa to persist in a chronic infection.

\section{Synthesis of HAQs Analogs of Burkholderia are also Inhibited by 2-AA}

Production of the 2-AA has been reported in plants, invertebrate animals, and vertebrate animals, including humans [41]. Moreover, several plant and human eubacterial pathogens, including Pseudomonas, Bordetella, Burkholderia, Ralstonia, Streptomyces, and Mycobacteria, as well as the Archeae Sulfolobus, encode putative PqsA and MvfR homologues, and in some cases, pqsBCD-related loci [42]. As such, these species might also produce 2-AA and use this molecule to down-regulate their respective virulence functions. Indeed, Burkholderia thailandensis, highly related and often used as a non-pathogenic surrogate for the level 3 pathogen $B$. pseudomallei, was confirmed to produce 2-AA (Figure S1). We assessed whether this 2-AA could inhibit HAQ biosynthesis in B. thailandensis, and found that exogenous 2-AA inhibited production of the HHQ and HNQ methylated analogs HMHQ and HMNQ (Figure S5A and B) [23], suggesting that 2-AA may perform analogous functions in B. thailandensis as observed in P. aeruginosa. 2-AA producing species may have a selective advantage in mixed microbial communities by adversely influencing the expression or activities of fitness traits of their neighbors.

Here we provide evidence that 2-AA, a small volatile molecule produced by $P$. aeruginosa (and $B$. thailandensis), is a QS regulated molecule and an important modulator of acute and chronic virulence functions. Although much work has focused on how QS cell-cell signaling leads to the activation of a plethora of virulence factors, little is known about the silencing of these factors. Degradation of AHL by an AHL acylase [43] and interference of LasR and RhlR binding to their promoter by the transcription factors QscR [44] and RsaL [45] have been shown to downregulate AHL mediated QS. We recently demonstrated the existence of an interplay between QS systems, their components, and environmental factors that negatively impact HAQs [27]. However, no signaling molecule has been identified to date that negatively regulates acute virulence QS related functions or promotes bacterial adaptation and long-term persistence. Furthermore, no volatile compounds have been reported to be involved in 
A

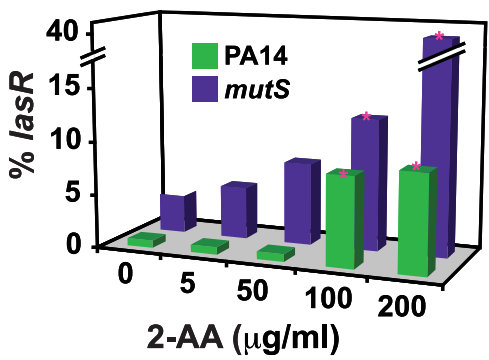

B

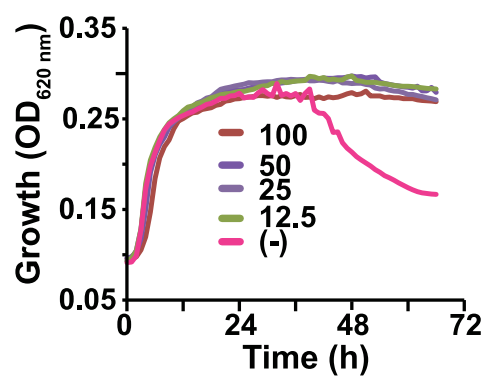

C

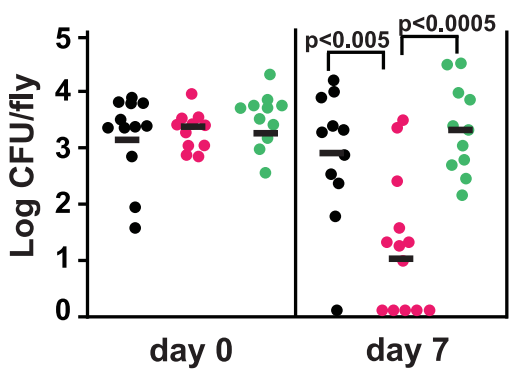

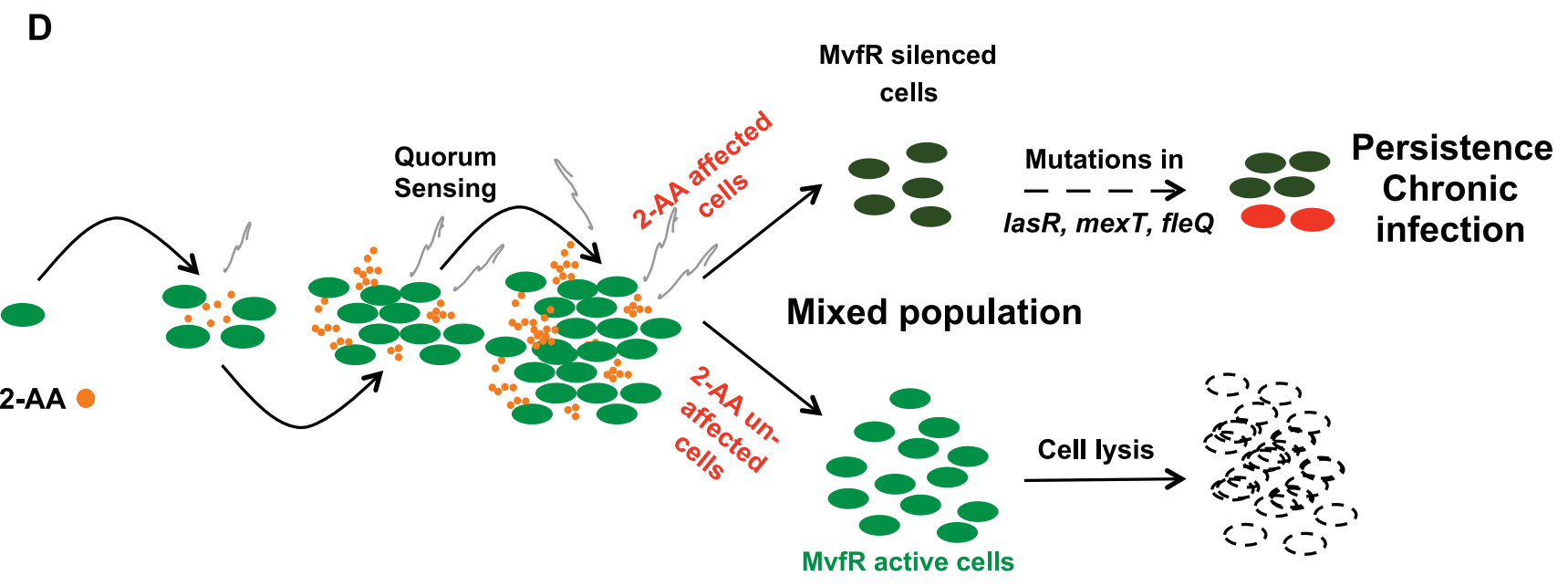

Figure 5. 2-AA promotes phenotypes associated with pathogenic bacteria at chronic infection sites. (A) 2-AA promotes increased accumulation of lasR mutations in PA14 and mutS cells in a concentration-dependent manner. Data are averages of two independent experiments, performed in triplicate. Significance of difference in number of las $R$ mutants was calculated using Student's $t$-test, assuming equal variance. Asterisks represent significant differences relative to the untreated control group. For both PA14 and mutS mutant cells, lasR mutant accumulation was significantly increased with $100 \mu \mathrm{g} / \mathrm{ml}$ and $200 \mu \mathrm{g} / \mathrm{ml} 2-\mathrm{AA}$ ( $p^{\prime} s=0.02$ and 0.0001 for PA14, and $p^{\prime} s=0.05$ and 0.01 for mutS, respectively). (B) 2-AA promotes prolonged stationary phase growth. Untreated PA14 cells began to lyse by $40 \mathrm{~h}$, whereas PA14 cells treated with 2-AA at all tested concentrations did not. (C) 2-AA promotes persistent infection in flies. Bacterial CFUs per fly were assessed at $7 \mathrm{~d}$ post- $P$. aeruginosa feeding (6-9 flies per time point). Significant differences in CFUs after $7 \mathrm{~d}$ were seen for $p q s A$ (pink) versus PA14 (black) or pqsB::C (green); Student's t-test $p$ values are indicated in the figure. The data presented were combined from two independent experiments. (D) A model for 2-AA function. As the volatile (squiggly grey lines) 2-AA accumulates overtime in a microenvironment (i.e. biofilms, wounds or CF lungs) it creates a heterogeneous population of cells that consists of WT and physiologically and genetically different cells. The unaltered WT cells undergo lysis. On the other hand, the subpopulation of cells with silenced MvfR can continue to accumulate mutations that are beneficial for adaption to chronic infection. doi:10.1371/journal.ppat.1002192.g005

QS regulation and virulence. Our results demonstrate that the low molecular weight molecule 2-AA silences the MvfR regulon via a negative feedback mechanism, most likely via repressed synthesis of MvfR ligands transcriptionally and post-transcriptionally, which restricts HAQ-mediated QS signaling and thus acute virulence functions, thereby enabling chronic infection. We propose the idea that there may be QS regulated aerial communication among bacteria, as 2-AA is a QS-regulated molecule and a volatile signal [46]. Such aerial communication may occur and be critical in a microenvironment such as the one found in biofilms and in infected wounds or CF lungs. It is important to note that suboptimal inhibitory concentration of 2-AA affects only a subpopulation of cells, suggesting that MvfR active and inactive cells co-exist causing a bistable phenotype. Similar bi/multistability phenotypes have been described as naturally occurring for several well known systems regulated by feedback mechanism, such as regulation of the Lac operon in E. coli, mucoidy in $P$. aeruginosa, lysogeny of the lambda phage, and transformation competency and sporulation in B. subtilis [24,47]. In our model
(Figure 5D), we propose that 2-AA inhibits MvfR via feedback regulation and promotes longer cell survival in vitro and in vivo in flies, presumably by interfering with cell lysis and inducing mutations in las $R$. Additionally, the accumulation of las $R$ mutations that allow adaptation to low oxygen conditions [48] suggest that this mechanism contributes to overall pathogen fitness in chronic infections. Whether, las $R$ mutations arise in WT cells, MvfR silenced cells, and/or metabolically altered cells, remains to be determined. In corroboration, the Drosophila persistence assay showed that 2-AA promotes bacterial long-term survival and as such fitness.

Assessment of the potential role of 2-AA in the establishment and persistence of chronic infections has been hindered by a lack of clinically relevant chronic infection models. Nevertheless, the Drosophila persistence assay, using 2-AA producing and nonproducing isogenic strains, permits us to at least determine the impact of this small molecule in a dynamic host environment that shares many immune functions with the human. Our identification of a $P$. aeruginosa QS regulated volatile molecule that limits 
Table 1. List of clones bearing las $R$, mexT, and fleQ mutations.

\begin{tabular}{llll}
\hline $\begin{array}{l}\text { Number of } \\
\text { clones }\end{array}$ & $\begin{array}{l}\text { Nucleotide } \\
\text { position in las } R\end{array}$ & $\begin{array}{l}\text { Sequence } \\
\text { change }\end{array}$ & $\begin{array}{l}\text { Amino acid } \\
\text { change }\end{array}$ \\
\hline 1 & T452 & $\Delta$ & Frameshift \\
2 & C192G & C-G & Stop \\
1 & C174G & C-G & Ala-Gly \\
$2^{*(2)}$ & T215 & $\Delta$ & Frameshift \\
1 & C692T & C-T & Ala-Val \\
1 & C471G & C-G & Stop \\
4 & G661T & G-T & Val-Leu \\
1 & T235C & T-C & Cys-Arg \\
$2^{*(2)}$ & $55-59$ & $\Delta$ & Frameshift \\
$11^{*(2) ~} \$(1)$ & $257-320$ & $\Delta$ & $\Delta 62$ \\
2 & $67-573$ & $\Delta$ & $\Delta 168$ \\
17 & Full gene & $\Delta$ & $\Delta$ full \\
\hline
\end{tabular}

Mutations in the mexT and fleQ intergenic regions are indicated by * and $\$$ respectively. The number in parentheses shows the number of clones bearing the respective mutation.

doi:10.1371/journal.ppat.1002192.t001

virulence and invasive functions associated with acute infections while promoting phenotypic and genetic changes associated with chronic infection elucidates novel avenues for combating bacterial adaptation and survival in the chronic infection environment. These results also suggest that interfering with the MvfR pathway could prevent both acute and chronic infections and that 2-AA synthesis provides a potential target for the development of new anti-virulence drugs in the combatance of $P$. aeruginosa, and possibly of other pathogenic bacteria such as Burkholderia. This study uncovers insights that paradigmatically pave the way for the search for 2-AA-like volatile small molecules that promote pathogen adaptation and establishment of chronic infections caused by foreboding human pathogens.

\section{Materials and Methods}

\section{Ethics Statement}

This study was carried out in strict accordance with the recommendations in the Guide for the Care and Use of Laboratory Animals of the National Institutes of Health. The protocol was approved by the Committee on the Ethics of Animal Experiments of the Massachusetts General Hospital (Permit Number: 2006N00 0093/2). All Procedures were performed under sodium pentobarbital anesthesia, and all efforts were made to minimize suffering.

\section{Bacterial Strains and Growth Conditions}

A P. aeruginosa strain known as Rif $^{\mathrm{R}}$ human clinical isolate UCBPPPA14 (PA14) was used in the present experiments [11]. All of the PA14 mutants described in this paper are isogenic to UCBPP-PA14. The bacteria were grown at $37^{\circ} \mathrm{C}$ on LB broth or on plates of $\mathrm{LB}$ agar containing appropriate antibiotics unless otherwise indicated. The overnight PA14 cultures were grown in LB and diluted the following day in fresh media with or without 2-AA. Bacterial growth kinetics was determined by taking $\mathrm{OD}_{600 \mathrm{~nm}}$ measurements.

\section{LC/MS}

Quantification of 2-AA and HAQs in bacterial culture supernatants was performed as described previously [14,49]. The HAQs were separated on a C18 reverse-phase column connected to a triple quadrupole mass spectrometer, using a water/acetonitrile gradient [49]. Positive electrospray in MRM mode with $2 \times 10^{-3}$ mTorr argon and $30 \mathrm{~V}$ as the collision gas and energy was employed to quantify $2-\mathrm{AA}$ and HAQs, using the following ion transitions: 2-AA 136>91, HHQ 244>159, HHQD4 248>163, PQS 260>175, and PQS-D4 264>179. To quantify HAQs, Pseudomonas PA14 cells were grown in LB supplemented with different concentrations of 2-AA (Sigma, USA), with untreated LB being used as a negative control. The culture supernatant was collected at different stages of growth mixed with an equal volume of methanol, and the compounds were analyzed by LC/MS. All samples were analyzed in triplicate.

\section{Bacterial Growth Curves}

Bacterial cells were diluted 1/100 from overnight cultures and grown in six replicates in $20 \mu \mathrm{l}$ in a 96-well plate (Corning, Inc., Corning, NY). Bacterial growth was measured as a function of optical density at $\mathrm{OD}_{600 \mathrm{~nm}}$ using Tecan F200 automated plate reader (Infinite F200, Tecan Group Ltd, Männedorf, Switzerland).

For the $p q s A-s u c B$ assay, the bacteria were diluted from overnight cultures to $\mathrm{OD}_{600 \mathrm{~nm}} 0.1$ in $\mathrm{NaCl}$-free $\mathrm{LB}$ with tetracycline $(50 \mu \mathrm{g} / \mathrm{ml})$ and grown (Sigma, USA), with or without $10 \%$ sucrose $(200 \mu \mathrm{l})$. Growth was measured in triplicate every $30 \mathrm{~min}$ for up to $25 \mathrm{~h}$, using a Sunrise plate reader (Tecan Group Ltd, Männedorf, Switzerland).

For lysis experiments, the LB medium was treated with Chelex 100 resin 100-200 mesh, sodium glutamate (50 g/l)(BioRad, Hercules, CA) for $1 \mathrm{~h}$ followed by filtration with $0.2 \mu \mathrm{m}$ filters (Corning, NY). Bacterial cells were diluted $1 / 100$ in presence of various concentrations of 2AA. Triplicates ( $200 \mu \mathrm{l}$ volumes) were inoculated in 96 wells plates. The plates were incubated and growth was recorded every 30 min for $3 \mathrm{~d}$ using a Sunrise plate reader (Tecan Group Ltd, Männedorf, Switzerland).

\section{pqsA-GFP(ASV) Fluorescence Measurement and pqsA- LacZ, ß-galactosidase Assay}

PA14 or pqsA::pqsH cells carrying pAC37 plasmids with pqsA promoter fused to short-lived GFP $\{p q s A-\mathrm{GFP}(\mathrm{ASV})\}[50]$ were grown overnight in LB supplemented with gentamycin $(50 \mu \mathrm{g} / \mathrm{ml})$. The cultures were diluted in the morning with the test compound at desired concentrations and aliquoted $(200 \mu \mathrm{l})$ into 6 replicates in a 96-well assay plate (Corning, Inc. Corning, NY). Green fluorescent protein (GFP) fluorescence (excitation at $485 \mathrm{~nm}$, emission at $535 \mathrm{~nm}$ ) and $\mathrm{OD}_{600 \mathrm{~nm}}$ for growth was measured every $30 \mathrm{~min}$ using a Tecan F200 automated plate reader (Infinite F200, Tecan Group Ltd, Männedorf, Switzerland). Values presented were above the background fluorescence from the empty strain. For measurement of $B$-galactosidase activity, pqsA::pqs $H$ cells harboring pGX5, which carries the $p q s A$-lac $Z$ reporter gene [51], were diluted to $\mathrm{OD}_{600 \mathrm{~nm}}=0.05 ;$ and $\mathrm{OD}_{600 \mathrm{~nm}}$ and $\beta$-galactosidase activity (expressed as Miller Units) were measured at the indicated optical densities. Assays were performed in triplicate. All of the experiments were repeated at least three times.

\section{Construction of pqsB::C}

The mutant was constructed as described by Lesic et al [52] such that most of the $p q s B$ and $p q s C$ genes were replaced with a Kanamycin resistance marker. The deletion was made from nt 151 in $p q s B$ to nt 456 in $p q s C$ (within the coding regions), leaving $150 \mathrm{bp}$ of the $5^{\prime}$ end of the $p q s B$ coding region and $149 \mathrm{bp}$ of the $3^{\prime}$ end of the pqs $C$ coding region. The mutants were selected on LB plates containing Kanamycin $(200 \mu \mathrm{g} / \mathrm{ml})$. 


\section{Visualization of 2-AA Affected Cells}

PA14 cells harboring the plasmid pAC37, which contained the pqsA-GFP(ASV) reporter fusion, were grown to mid-logarithmic phase in the presence of various concentrations of 2-AA. The cells were washed in phosphate buffered saline (PBS) and their membranes were stained with FM-64 (Invitrogen) according to the manufacturer's instructions. Five-microliter aliquots of bacterial cells were spotted onto slides and covered with PolyL-lysine coated coverslips (Sigma Aldrich, US). The bacteria were visualized using an Eclipse E800 (Nikon) microscope with FM-64stained membranes visualized as red and $p q s A-G F P$ visualized as green. The pictures were processed using Spot V4.0.9 (Diagnostic Instruments) software.

\section{Plasmid Construction}

To constitutively express pqsABCD, a genomic fragment containing pqsABCD was amplified by PCR using pqsABamHI 5' CATGGatCGAaGGTTCTGTCATGTCGACG3' and PqsDP st1 5'CGACTGCAGTCAACATGGCCGGTTCAC3' primers from an H44 cosmid [53] as template. The BamH1 and Pstl digested PCR product was ligated to a $\mathrm{pDN} 18$ vector digested with BamH1 and Pst1. The construct was introduced into E. coli Top10 (Invitrogen) cells and $P$. aeruginosa $m v f R$ mutant cells by electroporation.

To construct $p q s A-s u c B$ reporter fusion, the $p q s A$ promoter was amplified using the primers 5'GACTAGTCGAGCAAGGGTTGTAACGGTTTTTG3' and 5'GAAGATCTGACAGAACGTTCCGTCTTCAGCGA3' and the PA14 chromosome was used as template. The $s a c B$ gene was amplified using the primer pairs 5'GAAGATCTATGAACATCAAAAAGTTTGGA3' and 5'AAACTGCAGGTTGATAAGAAATAAAAGAAAATGCC3' from pKOBEG-sacB plasmid [54]. PqsA promoter (PpqsA) was then digested with SpeI/BglII and the fragment containing sacB was digested with BglII/PstI. The two fragments were ligated to the GTX (TetR) plasmid digested with SpeI/BglII. The ligated vector was eletroporated into $E$. coli SM10 lambda pir and used to integrate the CTX-PpqsA-sacB to PA14 chromosome. Rif and TetR plates were used to select for the PA14 CTX-P $p q s A$-sacB clones and the presence of CTX-PpqsA-sacB in the PAl4 chromosome was further confirmed by PCR.

\section{Pyocyanin Quantification}

Overnight PA14 cultures were diluted to $\mathrm{OD}_{600 \mathrm{~nm}}=0.05$ in $5 \mathrm{ml} \mathrm{LB}$ or $\mathrm{LB}+200 \mu \mathrm{g} / \mathrm{ml} 2-\mathrm{AA}$. The bacteria were grown in triplicate at OD 3.0. Pyocyanin was extracted with chloroform from $5 \mathrm{ml}$ cell culture supernatant and then extracted with an equal volume of $\mathrm{HCl}(0.2 \mathrm{~N})$; optical density was measured at $\mathrm{OD}_{520 \mathrm{~nm}}$. The amount of pyocyanin was quantified by multiplying the $\mathrm{OD}_{520 \mathrm{~nm}}$ value by 17.072 to obtain values in $\mu \mathrm{g} / \mathrm{ml}[55]$.

\section{Pyoverdine Quantification}

PA14 bacterial cells $(200 \mu \mathrm{l})$ were grown in 96-well plates in DTSB medium with a range of 2-AA concentrations. The plates were incubated and pyoverdine production and growth were measured every 30 min by a Tecan F200 automated plate reader (Infinite F200, Tecan Group Ltd, Männedorf, Switzerland). Pyoverdine levels were measured using excitation at $400 \mathrm{~nm}$ and emission at $460 \mathrm{~nm}$. The values were normalized to cell growth $\left(\mathrm{OD}_{600} \mathrm{~nm}\right)$. Pyoverdine concentrations were calculated using a calibration curve of fluorescence for a range of pyoverdine concentrations (Sigma Aldrich, USA).

\section{Mortality Studies}

Fly mortality. Fly maintenance and the infection assays were performed as described previously [29]. For the survival assays, 50-60 flies were infected with a bacterial suspension of $5 \times 10^{7}$ cells $/ \mathrm{ml}$ (grown in $\mathrm{LB}$ to $\mathrm{OD}_{600 \mathrm{~nm}}=3.0$ ) in the presence (1.6 ng of $2-\mathrm{AA} / \mathrm{fly}$ ) and absence of $2 \mathrm{AA}$. The bacteria were mixed with 2-AA immediately before injection, and the flies were incubated at $21^{\circ} \mathrm{C}$ following infection. Fly mortality was assessed over time as described previously [29]. The experiment was performed twice with qualitatively similar results between the replicates. Bacterial inoculations were accomplished via pricking the middle dorsolateral thorax of the fly with a needle previously dipped into the bacterial suspension. The number of inoculated cells was $\sim 100(2 \mathrm{nl})$ on average per fly. Statistical significance of survival kinetics was assessed by the Kaplan Meier method.

Mouse mortality. A thermal injury mouse model [32] was used, as described previously [11], to assess bacterial pathogenicity in 6-week-old CD1 mice (Charles River, Boston, MA, USA). The animal protocol was approved by the Massachusetts General Hospital Institutional Animal Care and Use Committee. Following administration of anesthesia, a full-thickness thermal burn injury involving $5-8 \%$ of the total body surface area was produced on the dermis of the shaved mouse abdomen, and an inoculum of $2.5 \times 10^{5}$ PA14 cells in $100 \mu \mathrm{l}$ of saline or 2 -AA solution $67 \mu \mathrm{g}$ of 2 -AA in $100 \mu \mathrm{l}$ saline/mouse, mixture prepared immediately before injection) was injected intradermaly into the burn eschar. Mortality was recorded for 1 week. CFU counts were performed for 5-6 mice per group. Local muscle biopsies underneath the eschar, and from adjacent muscle on either side of the burn eschar, $20 \mathrm{~h}$ post-burn and infection were collected and homogenized in $1 \mathrm{ml}$ of $1 \times$ PBS. The samples were diluted and plated on LB-agar plates containing rifampicin $(50 \mathrm{mg} / \mathrm{L})$. The systemic spread of the bacteria was assessed by counting the CFUs in the blood at $20 \mathrm{~h}$ post-burn and infection.

\section{Fly Feeding Infection and Bacterial Persistence}

Fly feeding on a $P$. aeruginosa-containing solution was performed as described previously [28]. Briefly, 5-7-day-old female Oregon$\mathrm{R}$ flies $(\mathrm{N}=26$ per group) were fed for $1 \mathrm{~d}$ with a mixture of $0.05 \mathrm{ml}$ of $\mathrm{LB}$ bacterial culture at $\mathrm{OD}_{600 \mathrm{~nm}}=1.8,1 \mathrm{ml}$ of $20 \%$ sucrose, and $4 \mathrm{ml}$ of water. Thus, the feeding mix contained a final concentration of $1 \% \mathrm{LB}, \sim 3 \times 10^{7}$ bacteria $/ \mathrm{ml}$, and $4 \%$ sucrose. A sterile cotton ball was placed at the bottom of each fly vial and was impregnated with $5 \mathrm{ml}$ of the feeding mix. The flies in each treatment group were sub-divided into three fly vials (13 flies per vial), sealed with a clean cotton ball, and incubated at $25^{\circ} \mathrm{C}$. A day later, the flies were transferred to $50 \mathrm{ml}$ plastic screw-cap tubes $(10$ flies per tube). The tubes were perforated with a heated $0.9-\mathrm{mm}$ needle to enable aeration, while the caps were perforated with a heated 1.2-mm needle and covered with a $2.3 \mathrm{~cm}$ Whatman disc (Fisher scientific, USA). A $0.2-\mathrm{ml}$ volume of $4 \%$ sucrose solution was dropped onto the Whatman disc and covered with parafilm to provide food for the flies with minimal contamination. New fly tubes were prepared daily and the flies were incubated at $25^{\circ} \mathrm{C}$. CFU counts per fly were measured at the indicated time points by dipping 6-9 flies per time point in 95\% ethanol for $3 \mathrm{~s}$ and letting them dry out on paper tissues (Kimwipes). Then each fly was ground up using a 1.5-ml tube pestle in $0.1 \mathrm{ml}$ of $\mathrm{LB}$, and 1:10 dilutions were plated on LB plates. Statistical analysis of the CFU data was performed using the Student's t-test.

\section{Assessment of Mutations}

PA14 and mutS mutant were grown overnight in LB. The saturated culture was diluted 1:10 in triplicate in $4 \%$ sucrose with 
varying concentrations of 2-AA, or without 2-AA. The diluted cultures were incubated statically at $25^{\circ} \mathrm{C}$ for $10 \mathrm{~d}$. The cells were then diluted and plated to allow the numbers of total colonies to be counted the following day. After $2 \mathrm{~d}$ of plating, the las $R$ cells were identified by their excessive pyocyanin production. The percentage of las $R$ mutants in each sample was calculated and statistical significance was determined by Student's t-test, assuming equal variance. The las $R$ mutant colonies were further confirmed by sequencing of the complete las $R$ gene. In addition, the complete sequences of mexA, mexE, mexS, mex T, mexZ, wspF, fle $\mathrm{d}$ exs $A, \operatorname{acc} C$, $v f R, p o p D, m u t S, n f x B, r p o \mathcal{N}, r h l R, p q s A, p q s b, p q s E, p q s H$, and $m v f R$ were also determined in these las $R$ mutant colonies.

\section{Supporting Information}

Figure S1 Production Kinetics of 2-AA in Burkholderia thailandensis. Production kinetics of 2-AA at different stages of growth. Growth is shown as OD $600 \mathrm{~nm}$. The error bars represent the standard deviation from 3 replicates.

(EPS)

Figure S2 Levels of 2-AA in various isogenic mutants of $\boldsymbol{P A 1 4}$. 2-AA levels were quantified by LC/MS and presented as relative to WT (PA14) levels at OD 4.0.

(EPS)

Figure S3 DHQ does not affect the expression of the pqs $A$ promoter, neither 2-AA nor DHQ inhibit bacterial growth. (A) Expression of $p q s A-G F P(\mathrm{ASV})$ in the presence of increasing concentrations of DHQ measured as GFP fluorescence and expressed as relative fluorescence over time. (B and $\mathrm{C}$ ). Growth curve of PA14 cells carrying the pqsA-GFP(ASV). Growth

\section{References}

1. Bassler BL, Losick R (2006) Bacterially speaking. Cell 125: 237-246.

2. Smith EE, Buckley DG, Wu Z, Saenphimmachak C, Hoffman LR, et al. (2006) Genetic adaptation by Pseudomonas aeruginosa to the airways of cystic fibrosis patients. Proc Natl Acad Sci U S A 103: 8487-8492.

3. Goodman AL, Kulasekara B, Rietsch A, Boyd D, Smith RS, et al. (2004) A signaling network reciprocally regulates genes associated with acute infection and chronic persistence in Pseudomonas aeruginosa. Dev Cell 7: 745-754.

4. Hassett DJ, Korfhagen TR, Irvin RT, Schurr MJ, Sauer K, et al. (2010) Pseudomonas aeruginosa biofilm infections in cystic fibrosis: insights into pathogenic processes and treatment strategies. Expert Opin Ther Targets 14: 117-130.

5. Haussler S (2010) Multicellular signalling and growth of Pseudomonas aeruginosa. Int J Med Microbiol 300: 544-548

6. Mougous JD, Cuff ME, Raunser S, Shen A, Zhou M, et al. (2006) A virulence locus of Pseudomonas aeruginosa encodes a protein secretion apparatus. Science 312: 1526-1530.

7. Schobert M, Jahn D (2010) Anaerobic physiology of Pseudomonas aeruginosa in the cystic fibrosis lung. Int J Med Microbiol 300: 549-556.

8. Williams P, Camara M (2009) Quorum sensing and environmental adaptation in Pseudomonas aeruginosa: a tale of regulatory networks and multifunctional signal molecules. Curr Opin Microbiol 12: 182-191.

9. Shiner EK, Rumbaugh KP, Williams SC (2005) Inter-kingdom signaling: deciphering the language of acyl homoserine lactones. FEMS Microbiol Rev 29: 935-947.

10. Cao H, Krishnan G, Goumnerov B, Tsongalis J, Tompkins R, et al. (2001) A quorum sensing-associated virulence gene of Pseudomonas aeruginosa encodes a LysR-like transcription regulator with a unique self-regulatory mechanism. Proc Natl Acad Sci U S A 98: 14613-14618.

11. Rahme LG, Stevens EJ, Wolfort SF, Shao J, Tompkins RG, et al. (1995) Common virulence factors for bacterial pathogenicity in plants and animals. Science 268: 1899-1902.

12. Gallagher LA, McKnight SL, Kuznetsova MS, Pesci EC, Manoil C (2002) Functions required for extracellular quinolone signaling by Pseudomonas aeruginosa. J Bacteriol 184: 6472-6480.

13. Oglesby AG, Farrow JM. 3rd, Lee JH, Tomaras AP, Greenberg EP, et al. (2008) The influence of iron on Pseudomonas aeruginosa physiology: a regulatory link between iron and quorum sensing. J Biol Chem 283: 15558-15567.

14. Xiao G, Deziel E, He J, Lepine F, Lesic B, et al. (2006) MvfR, a key Pseudomonas aeruginosa pathogenicity LTTR-class regulatory protein, has dual ligands. Mol Microbiol 62: 1689-1699. is represented as the OD $600 \mathrm{~nm}$ with increasing concentration of DHQ (B) and 2-AA $(\mathrm{C})$ respectively. The values presented are average from 6 replicates.

(EPS)

Figure S4 Growth Kinetics of PA14 and pqsB:: $C$ mutant carrying pqsA-SacB reporter. Growth (OD $600 \mathrm{~nm}$ ) was recorded in the presence or absence of sucrose $(10 \%)$ and/or with exogenously added various concentrations of 2 -AA. The pqsA promoter of $p q s A-S a c B$ in the $p q s B C$ mutant was induced by exogenous addition of $10 \mu \mathrm{g} / \mathrm{ml}$ HHQ where indicated. The vertical line represents the growth at 20 hours post inoculation. (EPS)

Figure S5 2-AA inhibits the HAQ analogs in $B$. thailandensi. Production kinetics of HMHQ $(\mathbf{A})$ and HMHNQ $(\mathbf{B})$ in $B$. thailandensis supernatants at different growth stages, minus and plus 2-AA. LC/MS data are averaged for triplicate samples.

(EPS)

\section{Acknowledgments}

We thank Dr. Tim Tolker-Nielsen for the plasmid with pqsA-GFP(ASV), Khwaja Fahad Haq for technical help, and Melissa Starkey for critical comments on the manuscript.

\section{Author Contributions}

Conceived and designed the experiments: MK LGR. Performed the experiments: MK RH JH YA YQ BL GX VD SM. Analyzed the data: MK ED FL LGR. Contributed reagents/materials/analysis tools: FL LGR. Wrote the paper: MK LGR.
15. Deziel E, Lepine F, Milot S, He J, Mindrinos MN, et al. (2004) Analysis of Pseudomonas aeruginosa 4-hydroxy-2-alkylquinolines (HAQs) reveals a role for 4-hydroxy-2-heptylquinoline in cell-to-cell communication. Proc Natl Acad Sci U S A 101: 1339-1344.

16. Deziel E, Gopalan S, Tampakaki AP, Lepine F, Padfield KE, et al. (2005) The contribution of MvfR to Pseudomonas aeruginosa pathogenesis and quorum sensing circuitry regulation: multiple quorum sensing-regulated genes are modulated without affecting lasRI, rhlRI or the production of $\mathrm{N}$-acyl-Lhomoserine lactones. Mol Microbiol 55: 998-1014.

17. Wade DS, Calfee MW, Rocha ER, Ling EA, Engstrom E, et al. (2005) Regulation of Pseudomonas quinolone signal synthesis in Pseudomonas aeruginosa. J Bacteriol 187: 4372-4380.

18. Cox CD, Parker J (1979) Use of 2-aminoacetophenone production in identification of Pseudomonas aeruginosa. J Clin Microbiol 9: 479-484.

19. Lepine F, Milot S, Deziel E, He J, Rahme LG (2004) Electrospray/mass spectrometric identification and analysis of 4-hydroxy-2-alkylquinolines (HAQs) produced by Pseudomonas aeruginosa. J Am Soc Mass Spectrom 15: 862-869.

20. Lepine F, Dekimpe V, Lesic B, Milot S, Lesimple A, et al. (2007) PqsA is required for the biosynthesis of 2,4-dihydroxyquinoline (DHQ), a newly identified metabolite produced by Pseudomonas aeruginosa and Burkholderia thailandensis. Biol Chem 388: 839-845.

21. Labows JN, McGinley KJ, Webster GF, Leyden JJ (1980) Headspace analysis of volatile metabolites of Pseudomonas aeruginosa and related species by gas chromatography-mass spectrometry. J Clin Microbiol 12: 521-526.

22. Scott-Thomas AJ, Syhre M, Pattemore PK, Epton M, Laing R, et al. (2010) 2 Aminoacetophenone as a potential breath biomarker for Pseudomonas aeruginosa in the cystic fibrosis lung. BMC Pulm Med 10: 56

23. Vial L, Lepine F, Milot S, Groleau MC, Dekimpe V, et al. (2008) Burkholderia pseudomallei, B. thailandensis, and B. ambifaria produce 4-hydroxy-2alkylquinoline analogues with a methyl group at the 3 position that is required for quorum-sensing regulation. J Bacteriol 190: 5339-5352.

24. Thattai M, van Oudenaarden A (2004) Stochastic gene expression in fluctuating environments. Genetics 167: 523-530.

25. Lesic B, Lepine F, Deziel E, Zhang J, Zhang Q et al. (2007) Inhibitors of pathogen intercellular signals as selective anti-infective compounds. PLoS Pathog 3: 1229-1239.

26. Farrow JM. 3rd, Sund ZM, Ellison ML, Wade DS, Coleman JP, et al. (2008) PqsE functions independently of PqsR-Pseudomonas quinolone signal and enhances the rhl quorum-sensing system. J Bacteriol 190: 7043-7051. 
27. Hazan R, He J, Xiao G, Dekimpe V, Apidianakis Y, et al. (2010) Homeostatic Interplay between Bacterial Cell-Cell Signaling and Iron in Virulence. PLoS Pathog 6: e1000810.

28. Apidianakis Y, Pitsouli C, Perrimon N, Rahme L (2009) Synergy between bacterial infection and genetic predisposition in intestinal dysplasia. Proc Natl Acad Sci U S A.

29. Apidianakis Y, Rahme LG (2009) Drosophila melanogaster as a model host for studying Pseudomonas aeruginosa infection. Nat Protoc 4: 1285-1294.

30. Lau GW, Goumnerov BC, Walendziewicz CL, Hewitson J, Xiao W, et al. (2003) The Drosophila melanogaster toll pathway participates in resistance to infection by the gram-negative human pathogen Pseudomonas aeruginosa. Infect Immun 71: 4059-4066.

31. Ferrandon D, Imler JL, Hetru C, Hoffmann JA (2007) The Drosophila systemic immune response: sensing and signalling during bacterial and fungal infections. Nat Rev Immunol 7: 862-874.

32. Stevens EJ, Ryan CM, Friedberg JS, Barnhill RL, Yarmush ML, et al. (1994) A quantitative model of invasive Pseudomonas infection in burn injury. J Burn Care Rehabil 15: 232-235.

33. D'Argenio DA, Wu M, Hoffman LR, Kulasekara HD, Deziel E, et al. (2007) Growth phenotypes of Pseudomonas aeruginosa lasR mutants adapted to the airways of cystic fibrosis patients. Mol Microbiol 64: 512-533.

34. Nguyen D, Singh PK (2006) Evolving stealth: genetic adaptation of Pseudomonas aeruginosa during cystic fibrosis infections. Proc Natl Acad Sci U S A 103: 8305-8306.

35. Mathee K, Narasimhan G, Valdes C, Qiu X, Matewish JM, et al. (2008) Dynamics of Pseudomonas aeruginosa genome evolution. Proc Natl Acad Sci U S A 105: 3100-3105.

36. Jain M, Ramirez D, Seshadri R, Cullina JF, Powers CA, et al. (2004) Type III secretion phenotypes of Pseudomonas aeruginosa strains change during infection of individuals with cystic fibrosis. J Clin Microbiol 42: 5229-5237.

37. Oliver A, Canton R, Campo P, Baquero F, Blazquez J (2000) High frequency of hypermutable Pseudomonas aeruginosa in cystic fibrosis lung infection. Science 288: $1251-1254$

38. Macia MD, Blanquer D, Togores B, Sauleda J, Perez JL, et al. (2005) Hypermutation is a key factor in development of multiple-antimicrobial resistance in Pseudomonas aeruginosa strains causing chronic lung infections. Antimicrob Agents Chemother 49: 3382-3386.

39. Kohler T, Epp SF, Curty LK, Pechere JC (1999) Characterization of MexT, the regulator of the MexE-MexF-OprN multidrug efflux system of Pseudomonas aeruginosa. J Bacteriol 181: 6300-6305.

40. Jyot J, Dasgupta N, Ramphal R (2002) FleQ the major flagellar gene regulator in Pseudomonas aeruginosa, binds to enhancer sites located either upstream or atypically downstream of the RpoN binding site. J Bacteriol 184: 5251-5260.
41. Tulp M, Bohlin L (2005) Rediscovery of known natural compounds: nuisance or goldmine? Bioorg Med Chem 13: 5274-5282.

42. Diggle SP, Lumjiaktase P, Dipilato F, Winzer K, Kunakorn M, et al. (2006) Functional genetic analysis reveals a 2-Alkyl-4-quinolone signaling system in the human pathogen Burkholderia pseudomallei and related bacteria. Chem Biol 13: 701-710.

43. Sio CF, Otten LG, Cool RH, Diggle SP, Braun PG, et al. (2006) Quorum quenching by an N-acyl-homoserine lactone acylase from Pseudomonas aeruginosa PAO1. Infect Immun 74: 1673-1682.

44. Chugani SA, Whiteley M, Lee KM, D’Argenio D, Manoil C, et al. (2001) QscR, a modulator of quorum-sensing signal synthesis and virulence in Pseudomonas aeruginosa. Proc Natl Acad Sci U S A 98: 2752-2757.

45. de Kievit T, Seed PG, Nezezon J, Passador L, Iglewski BH (1999) RsaL, a novel repressor of virulence gene expression in Pseudomonas aeruginosa. J Bacteriol 181: $2175-2184$

46. Schulz S, Dickschat JS (2007) Bacterial volatiles: the smell of small organisms. Nat Prod Rep 24: 814-842.

47. Balaban NQ, Merrin J, Chait R, Kowalik L, Leibler S (2004) Bacterial persistence as a phenotypic switch. Science 305: 1622-1625.

48. Hoffman LR, Richardson AR, Houston LS, Kulasekara HD, MartensHabbena W, et al. (2010) Nutrient availability as a mechanism for selection of antibiotic tolerant Pseudomonas aeruginosa within the CF airway. PLoS Pathog 6: e1000712.

49. Lepine F, Deziel E, Milot S, Rahme LG (2003) A stable isotope dilution assay for the quantification of the Pseudomonas quinolone signal in Pseudomonas aeruginosa cultures. Biochim Biophys Acta 1622: 36-41.

50. Yang L, Barken KB, Skindersoe ME, Christensen AB, Givskov M, et al. (2007) Effects of iron on DNA release and biofilm development by Pseudomonas aeruginosa. Microbiology 153: 1318-1328.

51. Xiao G, He J, Rahme LG (2006) Mutation analysis of the Pseudomonas aeruginosa mvfR and pqsABCDE gene promoters demonstrates complex quorum-sensing circuitry. Microbiology 152: 1679-1686.

52. Lesic B, Rahme LG (2008) Use of the lambda Red recombinase system to rapidly generate mutants in Pseudomonas aeruginosa. BMC Mol Biol 9: 20.

53. He J, Baldini RL, Deziel E, Saucier M, Zhang O, et al. (2004) The broad host range pathogen Pseudomonas aeruginosa strain PA14 carries two pathogenicity islands harboring plant and animal virulence genes. Proc Natl Acad Sci U S A 101: 2530-2535.

54. Derbise A, Lesic B, Dacheux D, Ghigo JM, Carniel E (2003) A rapid and simple method for inactivating chromosomal genes in Yersinia. FEMS Immunol Med Microbiol 38: 113-116.

55. Kurachi M (1958) Studies of the biosynthesis of pyocyanine. II. Isolation and determination of pyocyanine. Bull Inst Chem Res 36: 174-187. 